\title{
Artikel
}

\section{Het transigeren in grote fraudezaken: een blik op de toekomst}

\author{
Mr. R.T. de Jong en prof. mr. R.M.I. Lamp*
}

\section{Inleiding}

Het schikken, transigeren, in grote fraudezaken en andere zaken van financieel-economische aard ${ }^{1}$ mag al lange tijd bijzondere aandacht genieten. Naar aanleiding van iedere "hoge transactie"2 volgde de afgelopen jaren steevast discussie over - onder meer - de legitimiteit, transparantie en rechtsbescherming (bij de totstandkoming) van dergelijke transacties. Een veelvuldig en breed bepleite oplossing die aan die zorgen het hoofd zou bieden, is de introductie van een gerechtelijk controlemoment. ${ }^{3}$

Na een daartoe strekkende motie van 22 november $2018,{ }^{4}$ kondigde de minister van Justitie en Veiligheid (de 'minister') op 19 december 2018 aan een regeling uit

Mr. R.T. de Jong is advocaat bij De Brauw Blackstone Westbroek N.V Prof. mr. R.M.I. Lamp is advocaat bij De Brauw Blackstone Westbroek N.V. en hoogleraar Financieel strafrecht aan de Vrije Universiteit Amsterdam.

1 Hieronder verstaan wij voor deze bijdrage ook milieuzaken.

2 Transacties ex artikel 74 Wetboek van Strafrecht ('Sr') die onder het bereik vallen van (voorlopers van) de Aanwijzing hoge transacties (Stcrt. 2020, 46166).

3 Zie bijvoorbeeld een selectie van bijdragen waarnaar het conceptwets voorstel verwijst: J.H. Crijns, De strafrechtelijke overeenkomst. De rechtsbetrekking met het Openbaar Ministerie op het grensvlak van publiek- en privaatrecht (diss. Leiden), Deventer: Kluwer 2010, p. 588-592; T. van Roomen \& A. Verbruggen, 'Corruptie: status quo en de toekomst', Tijdschrift voor Bijzonder Strafrecht \& Handhaving, 2015/6; K.C.J. Vriend, 'De hoge en bijzondere transactie: een pleidooi voor rechterlijke controle op de afdoening buiten geding', Tijdschrift voor Bijzonder Strafrecht \& Handhaving 2016/4 en G.J.M. Corstens, J. Borgers \& T. Kooijmans, Het Nederlands strafprocesrecht, Deventer: Kluwer 2018, hoofdstuk XVIII.4 te werken die voorziet in de gerechtelijke toetsing van hoge transacties. ${ }^{5}$ De voor te stellen regeling zou een 'raadkamerprocedure (...) waarbij de partijen (het openbaar ministerie en de verdachte) worden gehoord' ${ }^{6}$ kunnen introduceren waarin ' $[d]$ e rechter (...) de transactie marginaal [toetst]. ${ }^{7}$ Deze toets zou dan geschieden op basis van door het Openbaar Ministerie aangeleverde informatie, zonder nader onderzoek door de rechter. ${ }^{8}$ Totdat die wettelijke regeling er is, geldt de Aanwijzing hoge transacties, ${ }^{9}$ die voorziet in toetsing van voorgenomen hoge transacties door een onafhankelijke commissie. ${ }^{10}$

De door de minister aangekondigde regeling is inmiddels in concept gereed en met het conceptwetsvoorstel naar aanleiding van de evaluatie van de Wet OM-afdoening van 11 maart 202111 (het 'conceptwetsvoorstel') ter consultatie voorgelegd. De Raad voor de rechtspraak, de Nederlandse Orde van Advocaten, de Nederlandse Vereniging voor Rechtspraak, het Openbaar Ministerie en DeComplianceMonitor hebben zich in de inmiddels af-

Kamerstukken II 2018/19, 29279, nr. 478. Zie naar aanleiding hiervan ook: G.M. Verhage en M. 't Sas, 'De transactie voortaan semi-buitengerechtelijk? Aanbevelingen voor de aanstaande rechterlijke toets van de hoge en bijzondere transactie', Tijdschrift voor Sanctierecht \& Onderneming 2019, p. 76-86.

6 Idem, p. 9.

Ibidem.

Idem, p. 10.

Stcrt. 2020, 46166.

10 Zie hierover uitgebreid in dit tijdschrift: Mr. V.S.Y. Liem en Mr. L.J. Leijten, 'De nieuwe aanwijzing hoge transacties - een vertaling van staande praktijk?', Tijdschrift voor Bijzonder Strafrecht \& Handhaving 2020, p. 270273.

11 Conceptwetsvoorstel van wet tot wijziging van het Wetboek van Strafvordering en enkele andere wetten naar aanleiding van de evaluatie van de Wet OM-afdoening, 11 maart 2021 (online publiek). 
geronde consultatiefase (in meer of mindere mate) kritisch uitgelaten over het voorstel. ${ }^{12}$

Met het conceptwetsvoorstel neemt de minister afstand van het gedachtegoed van zijn (verre) voorganger, die zich ruim honderd jaar geleden uitsprak tegen het vereiste van een gerechtelijk 'fiat' voor transacties omdat dit: 'logisch zou (...) moeten leiden tot een proces - een rechter beslist na hoor en wederhoor -, terwijl men juist afdoening buiten proces wenscht'. ${ }^{13}$ Lange tijd is aan dat gedachtegoed niet of nauwelijks getornd, maar met de (toenemende) inzet van de transactiemodaliteit in omvangrijkere en complexere (fraude)zaken, veranderde dat - overigens al ver vóór de genoemde motie uit 2018. ${ }^{14}$ De gedachte bleef doorgaans dat ook met een gerechtelijke toets de transactiemodaliteit als zodanig zou blijven bestaan. ${ }^{15}$ Het is de vraag in hoeverre dat met de in het conceptwetsvoorstel voorgestelde regeling het geval kan zijn. Blijft de transactie een buitengerechtelijke afdoeningsmodaliteit (met een moment van gerechtelijke betrokkenheid) of verwordt het tot een pseudogerechtelijke procedure? We werpen met het oog op die vraag - na een korte beschrijving van de voorgestelde toetsingsprocedure -een blik vooruit.

\section{De raadkamertoets: doel en beschrijving van voorgestelde procedure}

De minister geeft in het conceptwetsvoorstel duidelijk aan dat de transactie moeilijk gemist kan worden voor de aanpak van financieel-economische criminaliteit. ${ }^{16}$ Het feit dat strafvervolging een zware wissel trekt op vervolgings- en zittingscapaciteit en dat over de afloop

12 Concept wetsvoorstel tot wijziging van het WvSv en enkele andere wetten naar aanleiding van de evaluatie van de Wet OM-afdoening, NOvA, advies van 3 mei 2021 aan de minister van Justitie en Veiligheid, Den Haag 2021 (online publiek); Advies wetsvoorstel naar aanleiding van de evaluatie van de Wet OM-afdoening, Raad voor de rechtspraak, advies van 4 mei 2021 aan de minister voor Rechtsbescherming, Den Haag 2021 (online publiek); Conceptwetsvoorstel tot wijziging van het WvSv en enkele andere wetten naar aanleiding van de evaluatie van de Wet OM-afdoening, NVvR, advies van 28 juni 2021 aan de minister van Justitie en Veiligheid, Den Haag 2021 (online publiek); Advies conceptwetsvoorstel tot wijziging van het WvSv en enkele andere wetten naar aanleiding van de evaluatie van de Wet OM-afdoening, Openbaar Ministerie, advies van 1 juni 2021, Den Haag 2021 (online publiek); en Reactie op het conceptwetsvoorstel n.a.v. de evaluatie van de Wet OM-afdoening, DeComplianceMonitor advies van 19 april 2021 aan de minister van Justitie en Veiligheid, Utrecht 2021 (online publiek)

13 Kamerstukken II 1919/20, 309, nr. 5, p. 17.

14 Zie bijvoorbeeld: Hoge Raad 13 mei 2005, Conclusie A-G Langemeijer, D.R. Doorenbos, 'Naming \& shaming', Serie Onderneming \& Recht, deel 38, Kluwer, Deventer, 2007, p. 43, M. Malsch, 'Geregisseerde openbaarheid - Het O.M. en de zichtbaarheid van transacties', Justitiële verkenningen 2005, nr. 6; G.J.M. Corstens, 'Transacties en openbaarheid', NJB $2001 / 2133$.

15 Zie bijvoorbeeld reeds in 2003: D.R. Doorenbos, 'Transacties in het ondernemingsstrafrecht', Tijdschrift voor onderneming en strafrecht 2003, p. $9 \& 12$.

16 Concept-MvT, p.2.
- ook voor de verdachte - onzekerheid blijft bestaan, speelt een belangrijke rol. ${ }^{17} \mathrm{Om}$ een efficiënte rechtsgang te creëren die aan deze (en andere) belangen recht kan doen, zoekt de minister aansluiting bij de beklagprocedure ex artikel 12 Wetboek van Strafvordering ('Sv'). Het conceptwetsvoorstel introduceert een toets waarbij het gerechtshof zowel de rechtmatigheid als de opportuniteit van toekomstige voorgenomen hoge transacties zou gaan beoordelen. ${ }^{18}$

Het conceptwetsvoorstel stelt daartoe een nieuwe rechtsgang voor, waarin - kort gezegd - de volgende stappen doorlopen moeten worden om tot een hoge transactie te kunnen komen:

1. De officier van justitie die een transactieaanbod wil doen, hoort de verdachte (bijgestaan door een advocaat) en maakt verslag op van dat verhoor, waaruit 'de zienswijze' van de verdachte blijkt. ${ }^{19}$

2. Rekening houdend met 'de uitkomst van het horen', formuleert de officier van justitie een voorlopig transactieaanbod en legt dat ter aanvaarding voor aan de verdachte. ${ }^{20}$

3. De verdachte aanvaardt het voorlopige transactieaanbod en bevestigt dat aan de officier van justitie.

4. De officier van justitie dient een met redenen omklede vordering tot het verlenen van verlof tot het doen van een transactieaanbod in bij het gerechtshof. Het Openbaar Ministerie overlegt daarbij in ieder geval (1) een feitenrelaas, (2) de erkenning van de geconstateerde feitelijke gedraging, (3) het verslag van het horen en (4) de inhoud van het voorlopige transactieaanbod. ${ }^{21}$

5. De officier van justitie deelt onverwijld de datum van de vordering tot verlofverlening mede aan de rechtstreeks belanghebbende(n) die hem bekend is, althans zijn. ${ }^{22}$

6. Het gerechtshof hoort, althans roept daartoe op, (1) de verdachte en (2) de rechtstreeks belanghebben$\mathrm{de}(\mathrm{n})$ die bekend is of zijn. ${ }^{23}$

7. Als het daartoe aanleiding ziet, kan het gerechtshof het Openbaar Ministerie vervolgens in de gelegenheid stellen het voorlopige transactieaanbod - en, zo lijkt ons, de onderbouwing daarvan - te wijzigen. De verdachte kan zijn zienswijze geven over daarop door het Openbaar Ministerie voorgestelde wijzigingen van het voorlopige transactieaanbod. ${ }^{24}$

8. Het gerechtshof toetst vervolgens het voorlopige transactieaanbod en oordeelt daarbij over de vraag (1) of is voldaan aan de wettelijke voorschriften voor het doen van een transactieaanbod en (2) of de officier van justitie bij afweging van alle in aanmerking

\footnotetext{
Ibidem.

8 Idem, p. 4.

19 Artikel 558 lid 1 en lid 2 Conceptwetsvoorstel.

Artikel 558 lid 3 en lid 4 Conceptwetsvoorstel.

21 Artikel 559 lid 1 en artikel 560 lid 1 Conceptwetsvoorstel.

2 Artikel 559 lid 3 Conceptwetsvoorstel.

Artikel 561 lid 1 en lid 2 Conceptwetsvoorstel.

Artikel 562 Conceptwetsvoorstel.
} 
komende belangen in redelijkheid tot het transactieaanbod heeft kunnen komen. ${ }^{25}$

9. Als (1) het gerechtshof verlof verleent voor het doen van het transactieaanbod, kan de officier van justitie het voorlopige transactieaanbod waartoe verlof is verleend gestand doen, of (2) als een dergelijk verlof niet wordt verleend, neemt de officier van justitie een nieuwe vervolgingsbeslissing, waar eenmaal opnieuw verlof voor kan worden gevraagd. ${ }^{26}$

De procedure, een raadkamerprocedure, vindt plaats achter gesloten deuren. ${ }^{27}$ Iedere beslissing over een verlofvordering - positief of negatief - wordt in het openbaar uitgesproken, (ook) aan de opgeroepen rechtstreeks belanghebbende(n) toegezonden en gepubliceerd op Rechtspraak.nl. ${ }^{28}$

Het conceptwetsvoorstel doet een paradoxale situatie ontstaan: om een strafzaak buiten rechte af te kunnen doen (het blijft uiteindelijk een afspraak tussen de verdachte en het Openbaar Ministerie) zal steeds een in potentie betrekkelijk uitgebreide gerechtelijke behandeling moeten plaatsvinden. Hoe uitgebreid, zal (ervan uitgaande dat het conceptwetsvoorstel in enige vorm wordt aangenomen) de praktijk leren. In dit verband is - onder meer - relevant (a) het toetsingskader voor de betrokken rechters en (b) de betrokkenheid van rechtstreeks belanghebbenden. Wij gaan daar hierna nader op in.

\section{De raadkamer: stempelmachine of kritische toetser?}

De voorgestelde beoordeling strekt zich uit tot zowel de rechtmatigheid (artikel 563 lid 3 onder (a)) als de opportuniteit (artikel 563 lid 3 onder (b)) van het voorlopige transactieaanbod. De minister geeft aan dat die beoordeling niet wezenlijk zal verschillen van de toetsingsbevoegdheid ex artikel $12 \mathrm{~Sv} .{ }^{29}$

Met de voorgestelde rechtmatigheidstoets zou de rechter gaan beoordelen of is voldaan aan de wettelijke voorschriften voor het doen van een transactieaanbod. Daarbij zou nagegaan moeten worden of het voorlopige aanbod conform de wettelijke regels tot stand is gekomen - bijvoorbeeld: is de verdachte gehoord en ligt er een

Conform artikel 22 lid 1 Sv. De Raad voor de rechtspraak heeft geadviseerd te expliciteren dat de behandeling inderdaad niet in het openbaar plaatsvindt (zie Advies wetsvoorstel naar aanleiding van de evaluatie van de Wet OM-afdoening, advies van de Raad voor de rechtspraak van 4 mei 2021 aan de minister voor Rechtsbescherming, Den Haag 2021 (online publiek), p. 5).

28 Artikel 564 lid 2 en lid 3 Conceptwetsvoorstel en Concept-MvT, p. 36.

29 Concept-MvT, p. 17. erkenning van het feitencomplex? Het gaat voor een deel om meer 'tick the box'-achtige vragen.

De rechter zal echter ook over meer fundamentele vragen een oordeel moeten vellen. In het bijzonder noemenswaardig is de vraag of de officier van justitie tot het oordeel heeft kunnen komen dat de geconstateerde gedraging bewijsbaar en strafbaar is (artikel 553 lid 1 onder c). Dit opent de deur voor in potentie vergaande betrokkenheid van het gerechtshof. De minister probeert die deur echter zoveel mogelijk gesloten te houden:

'Op basis van het feitenrelaas vindt een globale toetsing plaats van de aanwezigheid van voldoende bewijs in relatie tot het feit. Hierbij is geen sprake van een volledige toetsing in de zin van de artikelen 348 en 350 Sv.' 30

Bij die afstandelijke opstelling past het volgens de minister dat 'afwijzing van de vordering uitsluitend haar grond kan vinden in wezenlijke (procedurele) tekortkomingen'. ${ }^{31}$

Het is de vraag of de strafrechter zich zo lijdelijk zal (kunnen) opstellen. Een dergelijke opstelling zou ook minder goed passen bij de nog steeds in belangrijke mate inquisitoire strafrechtspleging in Nederland. Ook is die lastig te rijmen met de voorgestelde aansluiting bij de artikel 12 Sv-toets; in beklagzaken kan de rechter de beslissing van het Openbaar Ministerie nog steeds in volle omvang toetsen, en er zijn geen voornemens de toetsingsruimte te beperken. ${ }^{32}$ De rechter heeft - en behoudt - bovendien de mogelijkheid om ambtshalve andere stukken te verzoeken, voor zover dit voor de uit te voeren beoordeling noodzakelijk is (artikel 23 lid $1 \mathrm{~Sv}$ ), en hoeft zich dan ook niet te beperken tot de voorgestelde toetsing op basis van het feitenrelaas. ${ }^{33}$

De Raad voor de rechtspraak heeft zich in zijn wetgevingsadvies dan ook kritisch uitgelaten over de voorgestelde toetsingsruimte:

'De Raad vraagt zich af hoe deze uitwerking van de marginale toets zich verhoudt tot de in art. 553, eerste lid onder c vereiste voorwaarde dat de officier van justitie slechts een transactieaanbod met voorwaarden kan doen indien de geconstateerde feitelijke gedraging bewijsbaar en strafbaar is. Dat de rechter deze voorwaarde niet in zijn toets zou kunnen betrekken lijkt niet te verenigen met genoemde voorwaarde en de argumentatie voor de rechterlijke toets, te weten: legitimiteit, betere rechtsbescherming en transparantie van het proces. ${ }^{34}$

30 Ibidem

31 Concept-MvT, p. 34

32 Memorie van Toelichting van boek 3 Eindversie juli 2020 Modernisering Sv, p. 607. Zie uitgebreid over deze discussie bijvoorbeeld: Mr. dr. W. Geelhoed, 'De eeuwige discussie over de toetsingsomvang bij beklag tegen niet-vervolging', Platform Modernisering Strafvordering augustus 2019, DOI: 10.5553/PMSV/258950952019002008001.

33 Advies wetsvoorstel naar aanleiding van de evaluatie van de Wet OM-afdoening, advies van de Raad voor de rechtspraak van 4 mei 2021 aan de minister voor Rechtsbescherming, Den Haag 2021 (online publiek), p. 4-5.

34 Idem, p. 4. 
Daarbij verwijst de Raad ook naar de (mogelijkheid tot) toetsing in volle omvang in beklagprocedures. ${ }^{35}$ De Nederlandse Orde van Advocaten uit kritiek van gelijke strekking:

'Een volledige toets op de voet van artikel 12 Sv verdient de voorkeur. De rechter behoort geen stempelmachine te zijn en als verlof nodig wordt geacht zal de rechter ook een rol hebben te vervullen. Complicatie in dit verband is evident dat de rechter slechts een zeer beperkt overzicht krijgt van de strafzaak. Het verdient in zoverre aanbeveling bij de stukken die aan het hof worden aangeboden ook (verplicht) een overzicht (inhoudsopgave) te laten voegen van het strafdossier (een toevoeging op artikel 560 derhalve). Dit kan behulpzaam zijn om enig overzicht te krijgen in de (omvang van de) onderliggende strafzaak/het strafdossier en kan ook nut hebben ingeval het hof gebruik wil maken van de bevoegdheid nadere stukken op te vragen (artikel 23 lid 1). ${ }^{36}$

De toets zou zo dus - kort gezegd - ten minste meer dan een marginale moeten (kunnen) zijn. De Raad voor de rechtspraak adviseert verder om te verduidelijken dat het gerechtshof de vordering afwijst als de ter beschikking gestelde stukken (eventueel aangevuld na een ambtshalve verzoek daartoe ex artikel 23 lid 1 Sv) de rechter onvoldoende in staat stellen tot het uitvoeren van die toets. ${ }^{37}$

De Raad en de Orde werpen dogmatisch gezien legitieme bezwaren op, waaraan de minister lastig voorbij zal kunnen gaan. Mocht de toetsingsruimte overeenkomstig worden verruimd, dan kan dat in potentie substantiële impact hebben op - onder meer - de insteek van het strafrechtelijk onderzoek en de dynamiek tussen de verdachte en het Openbaar Ministerie in aanloop naar de totstandkoming van het voorlopige transactieaanbod. Deze partijen zullen zich immers moeten voorbereiden op een (min of meer) volledige herbeoordeling daarvan. We komen daar hierna in onze afsluitende vooruitblik op terug.

\section{Mate en moment van betrekken rechtstreeks belanghebbende(n)}

In de huidige transactieregeling is de officier van justitie gehouden het feit dat een transactie ter zake van een misdrijf is aangeboden onverwijld schriftelijk aan de hem bekende rechtstreeks belanghebbende(n) te melden. ${ }^{38} \mathrm{Bij}$ een hoge transactie gebeurt dat als de procedure zoals neergelegd in de Aanwijzing hoge transacties $^{39}$ - waaronder toetsing van de vervolgingsbeslissing door de toetsingscommissie - volledig is doorlopen en dus niets eraan in de weg staat de voorgenomen transactie aan te bieden. De huidige regeling ex artikel 74 lid $3 \mathrm{Sr}$ zou met het conceptwetsvoorstel van toepassing blijven voor transacties waarvoor geen verlof vereist is. ${ }^{40}$

Een geheel ander regime zou gaan gelden voor voorgenomen hoge transacties die wel door het gerechtshof moeten worden beoordeeld. Het conceptwetsvoorstel bepaalt namelijk dat iedere bekende rechtstreeks belanghebbende door de officier van justitie onverwijld op de hoogte wordt gebracht van het voorlopig transactieaanbod dat voor verlof is aangeboden. ${ }^{41}$ Iedere bekende rechtstreeks belanghebbende zal daarop ook door het gerechtshof worden gehoord, althans daartoe een oproep ontvangen. ${ }^{42} \mathrm{Op}$ dat moment kan de relevante rechtstreeks belanghebbende ook kennisnemen van op de zaak betrekking hebbende stukken, ${ }^{43}$ voor zover niet van kennisname uitgezonderd, bijvoorbeeld wegens zwaarwegende economische of financiële belangen van de relevante onderneming. ${ }^{44}$

Deze vroegtijdige betrokkenheid van rechtstreeks belanghebbende(n) is op zich goed verklaarbaar. Zouden zij pas nadat de transactie definitief tot stand is gekomen betrokken raken - door middel van een artikel 12-procedure - dan zou de beklagrechter de facto dezelfde toets nogmaals moeten uitvoeren. ${ }^{45}$ Het voorgestelde artikel 121 lid Sv (nieuw) zou daaraan in de weg gaan staan.

Hoewel begrijpelijk, brengt de vroegtijdige introductie van de rechtstreeks belanghebbende(n) belangrijke veranderingen mee in de dynamiek in (de aanloop naar) de toetsing van het voorlopige transactieaanbod. Afhankelijk van de zaak, kan een breed palet aan partijen zich op dat moment mengen in de discussie over c.q. beoordeling van de voorgenomen afdoeningswijze. Dit kan sterk van invloed zijn op de dynamiek in de afdoening van de strafzaak. Bovendien ontstaat de bijzondere situatie dat in de verlofprocedure een spreekrecht (zij het achter gesloten deuren) ontstaat voor een breder publiek dan wanneer de zaak op zitting zou worden afgedaan. Daar hebben immers slechts het slachtoffer en eventueel nabestaanden en/of ouders van minderjarige slachtoffers een spreekrecht. ${ }^{46}$
35 Ibidem.

36 Conceptwetsvoorstel tot wijziging van het WvSv en enkele andere wetten naar aanleiding van de evaluatie van de Wet OM-afdoening, NOvA advies van 3 mei 2021 aan de minister van Justitie en Veiligheid, Den Haag 2021 (online publiek), p. 2 en 8.

37 Advies wetsvoorstel naar aanleiding van de evaluatie van de Wet OM-afdoening, advies van de Raad voor de rechtspraak van 4 mei 2021 aan de minister voor Rechtsbescherming, Den Haag 2021 (online publiek), p. 4.

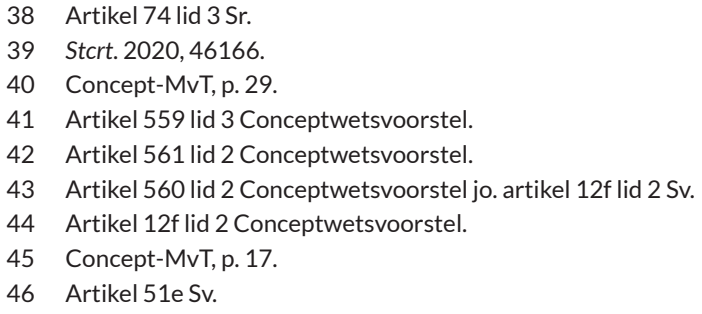




\section{Concluderende blik vooruit: buitengerechtelijke afdoening of afdoening buiten rechte na gerechtelijke behandeling?}

Zowel het Openbaar Ministerie als de verdachte zijn gebaat bij een efficiënte transactiemodaliteit waarmee relatief snel duidelijkheid kan worden verkregen over de afdoening van een strafzaak. De doelstelling zoals verwoord bij het conceptwetsvoorstel lijkt bij die gedachte nauw aan te sluiten, maar de uitwerking niet per se. Het zal interessant zijn om te zien hoe de toetsende rechter zich op zal stellen, waarbij wij op basis van het conceptwetsvoorstel en reacties daarop twee (uiterste) scenario's voorzien.

In het eerste (uiterste) scenario stelt de rechter zich op als spil in de pseudogerechtelijke afdoening van de strafzaak. Daarbij treedt hij op als proactieve scheidsrechter en vergt een oordeel over - onder meer - bewijs en strafbaarheid aan de hand van opgevraagde stukken uit het strafdossier en hoort hij rechtstreeks belanghebbenden, zoals maatschappelijke belangenorganisaties (ngo's), welke belangen hij meeweegt in zijn beoordeling van de opportuniteit van de vervolgingsbeslissing. Waar nodig stuurt hij het Openbaar Ministerie terug naar de tekentafel voor het formuleren van een nieuw voorlopig transactieaanbod dat aan zijn bezwaren tegemoet kan komen. De verdachte verkeert al die tijd in onzekerheid, maar heeft reeds een erkenning van het relevante feitencomplex op tafel moeten leggen. Rechtstreeks belanghebbenden hebben tegelijkertijd inzage in die erkenning en overige op de zaak betrekking hebbende stukken.

In het andere (uiterste) scenario treedt de rechter slechts op als globale toetser van het voorlopige transactieaanbod, waarbij hij de rechtmatigheid en opportuniteit daarvan beperkt verifieert aan de hand door het Openbaar Ministerie verstrekte informatie. Verklaringen van rechtstreeks belanghebbenden zullen in dat scenario slechts van invloed zijn indien zij blijk geven van een beslissing waartoe de officier in redelijkheid beslist niet had kunnen komen.

De praktijk zal zeer wel mogelijk ergens in het midden uitkomen en bovendien van zaak tot zaak verschillen. Dit kan voor zowel voor het Openbaar Ministerie als de verdachte tot grote bezwaren leiden, die uiteindelijk tot gevolg kunnen hebben dat eerder een gerechtelijke procedure wordt verkozen boven een pseudogerechtelijke. Het zou zonde zijn als dit het gevolg is van een regeling die juist strekt tot behoud van de transactiemodaliteit. 